Cylon Gonçalves da Silva. "CLIMBING MOUNT TERAWATT", p.35-40. In Luis Augusto Barbosa Cortez (Coord.).

Sugarcane bioethanol - R\&D for Productivity and Sustainability, São Paulo: Editora Edgard Blücher, 2014.

http://dx.doi.org/10.5151/BlucherOA-Sugarcane-SUGARCANEBIOETHANOL_7

\title{
CLIMBING MOUNT TERAWATT
}

\author{
Cylon Gonçalves da Silva
}

\section{INTRODUCTION}

In this book, the reader will find an extensive and rather complete compendium on the scientific, technical, social and economic challenges and opportunities for Brazilian sugarcane bioethanol, written by experts on the subject. This chapter, by a non-expert, is aimed at those readers who may still be asking themselves, but why sugarcane bioethanol? But, first, let us learn about Mount Terawatt.

It is no use searching in the old school Atlas or in Google Earth. Mount Terawatt (or simply TW) does not correspond to any geographical or geological landmark on the surface of our planet. It may still come to grace some mountain in a yet to be discovered planet, like those being discovered every day now, in which a small fraction of Mankind may seek refuge and a new start, far away from our old rock, eons from now. Mount Terawatt, for the moment, is simply one trillion (ten to the power twelve, one million million) Watts, a convenient unit to measure the amount of energy used by humans every second, because otherwise we would have to use very large numbers. (One Watt equals one joule per second, roughly one thousandth of a BTU per second.)

The 6.6 billion human beings use about 15 TW, i.e., on average, per person, 2,300 Watts (2.3 kW). This is about the power used by a large domestic electric oven, or, in poorer countries, a very good electric shower. Power, like wealth, is very unevenly distributed in the world. So, averages are almost meaningless. The average (North) American uses
$10 \mathrm{~kW}$ - but she is also a fiction - while a poor African will use no more than a few tens of Watts. Mount Terawatt is important for us because it is tall - the amount of power it represents is too much for us to have a simple intuitive representation of it - and because we use fossil fuels to climb it. As is well known, about $80 \%$ of all power generated in the world comes from fossil fuels.

It is not easy to generate $1 \mathrm{TW}$ of electrical power or liquid fuels. One TW of electricity requires the generating power of 1,000 "standard" nuclear power plants. So, if we took today the decision to generate 1 TW of nuclear electricity by 2050, aiming at replacing coal fueled power plants and avoiding $\mathrm{CO}_{2}$ emissions, we would have to open a new nuclear power plant every three days for 40 years! After all this, we would, sadly, find out that there is not enough uranium to fuel them for very long, but because the reasonably accessible uranium supplies in the world are rather small.

One TW of ethanol is equivalent to the consumption of 1.4 trillion liters in a year (370 billion gallons a year) or, if you like to think in $3 \mathrm{D}$, a cube with a $11.2 \mathrm{~km}$ (7 miles) edge. This is roughly 65 times the Brazilian bioethanol output in 2008 and a bit less than that of the US output. To generate 1 TW of bioethanol by 2050, the Brazilian output would have to grow at an average annual compound rate of $11 \%$, that is, to double every six and a half years. This is not an impossible goal to achieve, as this book shows, but it is a huge challenge. Climbing Mount Terawatt is not easy.

But the race to reach the summit of Mount Terawatt with carbon neutral or even carbon nega- 
tive power sources is on. Many believe, like the editors and authors of this book that the survival of our type of civilization and life style depends upon the success of this climb.

\section{TWO DISTINCT LIFE FORMS}

Two distinct life forms share the Earth: one natural, of which our species is part, and one artificial, created by us and without which we no longer know how to live. Using the term "life" here is a bit strong, because we normally associated it with organisms capable of reproduction and evolution. It is true that most of our machines do not share these potentialities with our pet dog, but this is not an essential limitation of the techno-industrial world. There are machines/organisms that already today straddle the gap between natural and artificial. What is a genetically modified organisms if not a machine capable of reproduction and evolution? Where is the essential difference between extracting a piece of iron ore from the ground and processing it into a ship, and extracting a piece of a gene from an organism, combining it with a piece of a gene from another and producing a third one? The processes, results, or risks may be very different, but it is the same scientific-technologicalindustrial view that governs these manipulations. The separation between natural and artificial is becoming smaller and smaller in our civilization and may have to disappear altogether, if we are to survive as a species on this planet. The natural world can no longer accommodate the demands of our insane and invasive species.

The point of this argument, however, is that the inhabitants of the artificial world share with us, humans, one fundamental characteristic: they only function thanks to a continuous flow of energy. In other words: they only function if they are well fed.

A normal adult requires about 2,500 kcal of energy per day. This translates into approximately 120 Watts. Assuming that all the 6.6 billion human beings fall into the "well fed" category (if only!), they would use $0.8 \mathrm{TW}$ of power to feed themselves. In this number, we are not taking into account the many other TW's needed to produce, process, preserve, transport, distribute, and prepare our food, nor the power needed to deal with the waste products resulting from all these processes. In comparison, the inhabitants of the parallel artificial world require 15 TW of power, that is, about 20 times the human demand. The slaves eat more than the masters, but, then, they work harder.

When we talk about the competition between food and bioenergy, we are talking about the competition between humans and machines for energy. This is a very unequal competition, because the machines need much more than we do. Maybe, one day, they will take over and put us on a very strict diet.

\section{A SINGLE SOURCE OF ENERGY AND ITS CONSEQUENCES}

In the natural world, there is only one source of power: the Sun. (We are excluding some minor sources of power, which, although extremely interesting from a fundamental point of view, do seem to be of no practical importance for the moment being.) Plants and other organisms capable of photosynthesis, which transform electromagnetic into chemical energy, directly use this power. All the rest of us, natural or artificial heterotrophs, live mostly off photosynthesis.

The solar power incident at the top of the atmosphere is of the order of 170,000 TW, that is, more then 10,000 times the present needs of our machines. Only about $70 \%$ of this power (120,000 TW) reaches the surface of the Earth, the remainder being reflected back to outer space. On the solid portion of the surface, the amount is about 40,000 TW. Still an ample quantity of power compared with our needs. However, this power can only be metabolized by photosynthetic organisms. So, we are in the same position as the Ancient Mariner, dying of thirst (for power) in an ocean (of power). One tenth of a percent of the solar power incident on land would be more than enough to satisfy the present and foreseeable needs of Mankind. This book tries to teach us ways in which we may drink from this ocean of power by harnessing the photosynthetic good will of plants.

Undoubtedly, machines capable of converting heat into work (and work into electricity) are the 
great discovery of Mankind. The proper feeding of these machines depends, at the present moment, on the existence of immense reservoir of solar power metabolized and stored under the form of reduced carbon atoms (carbon atoms with a lot of chemical energy to spare, usually by being bound to hydrogen atoms). Coal, oil, and natural gas are the fossilized remnants of photosynthetic organisms that lived tens to hundreds of millions of years ago, and that now feed our machines. As we do not like to eat this sort of deteriorated food, there is no competition between them and us. And that is good. But, there is a price to be paid for this convenience. Eighty percent (12 TW) of the power used by them in 2008 came from fossil fuels, which once consumed by our heat machines become low grade compounds of reduced carbon, mostly $\mathrm{CO}_{2}$ that increasingly litter the industrial civilization atmosphere. Although an essential ingredient in the photosynthetic synthesis of new biomass, the natural world cannot transform all of this $\mathrm{CO}_{2}$ back into reduced forms of carbon as fast as the artificial world breathes it out. As it accumulates in the atmosphere, it leads to more and more scientific and diplomatic meetings, to more and more concerned statements by governments, and more and more announcements of oil discoveries by oil companies. But very little meaningful actions, such as those which this book proposes to alleviate the risks of major climate changes.

A phenomenon similar to the one just described already happened on our planet. Until photosynthesis came along, organisms that drew their energy from chemical sources and lived without oxygen inhabited the natural world. Photosynthesis, on the other hand, has as a metabolic by product a potentially toxic gas: oxygen. As the concentration of oxygen in the atmosphere grew, the new life forms slowly smothered the old ones, which had to retreat to places like municipal solid waste disposal sites. Today, artificial organisms, with our complicity, are busily changing the composition of the atmosphere, but try as they might, $\mathrm{CO}_{2}$ concentrations will never reach the proportions of present day $\mathrm{O}_{2}$ concentrations, because there is not enough fossil fuel at their disposal. But they can do a lot of damage, if increasing temperatures lead to the release of vast quantities of methane stored in colder parts of the planet.

The fact is that we can no longer envisage life without machines, but also, it is becoming more difficult to envisage the continued use of fossil fuel fed machines. So, it is a matter of utmost urgency to find a healthier diet for them. This is where bioenergy, rather biomass energy, comes in. Instead of using fossil reduced carbon, biomass energy aims at providing us with plentiful freshly reduced carbon, whose return to the atmosphere as oxidized carbon will not alter the overall concentration of $\mathrm{CO}_{2}$. Let us take a brief look at the two major energy vectors that feed our machines: electricity and fuels.

\section{ELECTRICITY}

Electricity generation is responsible for one third of the energy emissions of $\mathrm{CO}_{2}$. Instead of being generated by fossil energies, mainly coal, electricity can be generated by hydro, nuclear, wind, solar, wave, and biomass energy. All of which can have a lesser impact on emissions of greenhouse gases. With all these different alternatives, why persist with coal and other fossil sources? In the first place, because coal is cheap (not taking into account the cost of cleaning up afterwards), easily available in the countries that most need it, and the technology for burning coal efficiently is available. In the second place, because there are limitations for the other choices: available resources, expensive technologies, or intrinsic to the source, such as low power density or intermittency that can make the climbing of mount Terawatt rather challenging.

To begin with, we can exclude geothermal and wave resources. They are too local and limited to have a global impact. Next, wind and solar suffer because of their intermittency - the wind does not always blow in the right direction with the right intensity and the Sun does not always shine. So, the utilization factor (ratio of average power actually generated over the installed generating capacity) of these sources tends to be low. It can be better for wind than for solar, something to be kept in mind! But, no country can depend on its electricity 
exclusively on such sources. Anyway, the Achilles' heel of electricity is storage. Unlike liquid fuels that we can put into a tank and withdraw on a need to use basis, electricity has to be used as it is generated. There are schemes for storing electricity, but either they are cumbersome and inefficient or only work for minute quantities, in relation to actual needs. Whoever solves the problem of storing a TWh of electricity shall inherit the Earth.

The projections for 2030 indicate a worldwide need for 33,000 TWh of electricity. This means some $20 \mathrm{TW}$ of generating capacity based on wind farms, which would occupy about 3.3 million sq. $\mathrm{km}$. (1.27 sq. mi.), at a cost of 40 trillion dollars for the generators alone. But, we would also need a vast intelligent grid capable of mining the necessary power among all the generators, switching from one site to another quickly, depending on the local wind conditions. Similar considerations apply to solar electricity, be it photovoltaic or thermal. We are left with nuclear, hydro, and biomass electricity.

Nuclear has the great advantage of a large utilization factor (larger than 80\%) to supply base loads. But, it has the disadvantages of nuclear waste that needs to be stored for centuries. To supply the same 33,000 TWh, in 2030, with modern day and foreseeable technologies, we would need 4,700 new nuclear plants, that is, a new one every three days, for 40 years! The known uranium resources could feed these plants for a couple of decades, at best, much less than their operational lifetimes. It is true that the technology can change and that the challenges of dealing with nuclear wastes can be tackled successfully, but this is very unlikely to happen soon. Electricity from nuclear fusion is the first cousin of electricity from nuclear fission. It has the advantage of abundant fuel supplies (it uses basically hydrogen nuclei and $\mathrm{H}$ is the most abundant chemical element in the Universe), but the technology is simply not there. Even the most ardent supporters of fusion, recognize that it will not be able to make an appreciable contribution to the world supply of electricity before the $22^{\text {nd }}$ century. And, the skeptics do not believe that it will happen even then.

Hydropower is clean, based on an established technology, can supply base load electricity, but... the resources are not enough. At most, we can count on 2 to 3 TW worldwide, enough to supply 7,000 to 10,000 TWh; far from the projected demand. In addition, lately ecologists have been fiercely opposing new hydroelectricity projects on the grounds of protecting biodiversity and the local environment. Between the little critters and the human species, they wisely settle for the former. In the long run, it is a safe bet.

Biomass is a nice option to supply carbon neutral base load electricity. To generate 33,000 TWh of electricity, we will require something of the order of 100,000 TWh of thermal power. Assuming $10 \mathrm{GJ} /$ ton for biomass, this implies 36 billion tons of biomass per year. Taking sugarcane as an example, at 80 tons per hectare and 7.5 GJ per ton, we would need 600 million hectares or 6 million $\mathrm{km}^{2}$ (2.3 million sq. mi.) of sugarcane plantations around the world. This is roughly a hundred times the present cultivated area in Brazil. This number is only approximate, it may be smaller or larger depending on the assumed energy densities and productivities, but it gives us a fair estimate of the area needed for generating 33,000 TWh of electricity from biomass in 2030. This is a very schematic reasoning, though, as the countries that will most consume electricity are also countries that have most severe restrictions to produce biomass (think China and India). But, for a country like Brazil, there would be no real difficulties to have all of its energy coming from renewable sources, provided Petrobras could live with that.

Electricity is expensive from the energetic point of view, and the electric car, a very bad solution (which does not mean that it will not be a popular success). None of the existing carbon neutral or carbon free alternatives for electricity generation can push out fossil fueled electricity in the near future. Local, cleaner, solutions are always very welcome. But, climbing mount Terawatt is not an easy task. The numbers shown are not going to be altered by small is beautiful, however. They might even get worse, as they depend only on the laws of thermodynamics and the availability of primary energy resources.

In spite of these somewhat gloomy numbers, there is still hope for fossil fuels. Let us capture 
and sequester, for many centuries, the final metabolic waste from our machines: oxidized carbon. But here, also, there are some "minor" difficulties. These technologies can only be employed for large fixed installations, not for the transportation sector, which contributes with a quarter of the total energy emissions. Unfortunately, these technologies are far from the deployment stage. Demonstrations plants for a million tons a year exist, but we need to sequester several billion tons a year. Storage for many centuries is an open question. Not to mention the overall costs.

\section{FUELS}

Liquid fuels move Mankind. In 2005, 144 EJ of oil (exajoules; 1 exajoule is equivalent to roughly one Quad - one quadrillion BTU) were used by the transport sector. This represents $60 \%$ of all the oil consumed in that year. In annualized power, 4.6 TW out of the total 15.3 TW of primary power, were used to move people and goods around. In 2007, non-fossil fuels contributed mere $1 \mathrm{EJ}$ to the same tasks. Thus, we can say, supported by solid statistics, that the living are more and more moved by fossils. A notion of much wider application than merely to the transport sector, unfortunately.

With $60 \%$ of all the oil, and with $40 \%$ of energy emissions being due to this primary source, the transport sector was responsible for $24 \%$ of the 27 billion tons of $\mathrm{CO}_{2}$ emitted in 2005. That is the price of our material and psychological dependency on mobility. Until the 2008 financial crisis, the demand from transport sector was projected to grow at $1.5 \%$ a year until 2030. As it seems that this crisis has not affected the largest developing countries so badly, we will keep the projection. Growth is good. But, 50\% of this growth is expected to come from fossil fuels, leading to an increase in emissions. Emissions are bad. Fifty percent? Is the glass half full or half empty? The other half of the growth will come from biofuels, the largest contribution being from bioethanol, a little from biodiesel, reaching something of the order of $5 \mathrm{EJ}$ in 2030. This book is a contribution to getting these projections out of the paper (sorry) and into the market. Hopefully, even increasing more substantially the contribution from biofuels to the transport sector.

The 10\% solution, a relatively modest proposal being examined in this book, is the energy equivalent concentration of bioethanol in gasoline that could be adopted worldwide in order to reduce slightly gasoline consumption and emissions by 2030 .

The volumetric energy density of ethanol is roughly $2 / 3$ that of gasoline. Hence, $10 \%$ of gasoline energy corresponds to about $14.3 \%$ in ethanol volume. In 2007, the United States consumed 540 billion liters of gasoline. Globally, we can estimate for the same year a consumption of about 2.2 trillion liters. The $10 \%$ solution would require, in 2007, 318 billion liters of ethanol, compared to the world production of 50 billion liters. In 2030, if the projected world economy growth materializes, the $10 \%$ solution would require 430 billion liters of ethanol. A productivity of 7,000 liters per hectare, currently achieved by the Brazilian producers, leads us to an estimate of 61.4 million hectares $\left(614.000 \mathrm{~km}^{2}\right)$ of land needed for feedstock production. If, as expected, improvements in current processes and new technologies result in a 10,000 liters per hectare productivity in the future, then 43 million hectares of land $\left(430.000 \mathrm{~km}^{2}\right)$ would be sufficient for the $10 \%$ solution. This shows how critical productivity is to reduce land use. A 100\% solution, which is not being contemplated, would require as much land as the one needed to supply global electricity demand exclusively from biomass (a solution which is also not being contemplated).

According to data from IEA World Energy Outlook 2008, it is possible to estimate that to increase the world production capacity of biofuels by 1 GJ it is necessary to invest US $\$ 60$. Hence, to increase production of bioethanol from 50 to 430 billion liters, at $22 \mathrm{MJ} /$ liter, US $\$ 500$ billion would be required. This investment, spread over a period of 20 years, would mean US $\$ 25$ billion/ year. A small number as far as worldwide energy investments are concerned.

According to FAO (United Nations Food and Agriculture Organization), Brazil has about 550 million hectares (Mha) of potential agricultural land, of which 300 Mha are classified as "without major restrictions". That is, there are no major 
social or environmental restrictions on the use of this land for agriculture, as well as there is enough water for cultivation. In 2005, the cultivated area in Brazil was a mere 58 Mha, of which about 6 Mha dedicated to sugarcane (roughly half of this area for bioethanol production, the remainder for other products, mainly sugar). Hence, the $10 \%$ solution looks perfectly feasible in terms of available land and investments. The production of 430 billion liters of bioethanol would occupy about $14 \%$ of the area considered "without major restrictions", not considering further improvements in agricultural and industrial productivities. This means 9.5 EJ of biofuels to replace gasoline consumption. Or, in power terms, $300 \mathrm{GW}$. It is not a huge amount, but it brings us one third up Mount Terawatt.

\section{FINAL CONSIDERATIONS}

The real challenges for bioenergy, as we tried to show briefly above, are not the numbers. They are social perceptions and the environment: sustainability, effective reduction of greenhouse gases, and the perceived competition with food production. This book looks into all of these aspects, in the hope of contributing to making modern bioenergy a realistic option for a cleaner world energy matrix in the near future. 